\title{
Automated Pipe Handling System Suitable for Retrofitting Servicing Rigs in China
}

\author{
Fang Tai'an ${ }^{1,2}$, Zhou Zhixiong ${ }^{1,2}$, Wu Changliang ${ }^{1, ~}{ }^{*}$, Lv Juan ${ }^{1}$, Zuo Weidong ${ }^{1}$ \\ ${ }^{1}$ CNPC Engineering Technology R\&D Company Ltd., Beijing, China \\ ${ }^{2}$ National Engineering Laboratory for Oil and Gas Drilling Technology, Beijing, China
}

\section{Email address:}

fangtaiandri@cnpc.com.cn (Fang Tai’an), zhouzhixiongdri@cnpc.com.cn (Zhou Zhixiong), wuchangliangdr@enpc.com.cn (Wu Changliang), ljdri@enpc.com.cn (Lv Juan), zuoweidongdr@enpc.com.cn (Zuo Weidong)

${ }^{*}$ Corresponding author

\section{To cite this article:}

Fang Tai'an, Zhou Zhixiong, Wu Changliang, Lv Juan, Zuo Weidong. Automated Pipe Handling System Suitable for Retrofitting Servicing Rigs in China. International Journal of Oil, Gas and Coal Engineering. Vol. 8, No. 1, 2020, pp. 10-16. doi: 10.11648/j.ogce.20200801.12

Received: October 17, 2019; Accepted: November 13, 2019; Published: January 13, 2020

\begin{abstract}
With the development of automated drilling technology, various automated pipe handling devices are constantly being introduced. It is an inevitable trend to apply these equipment on new drilling rigs, while it is also an important work to apply these new technologies and equipment to a large number of servicing rigs. At present, most of the existing drilling rigs in China do not have automatic pipe handling system. It is urgent to carry out automation retrofitting due to the poor field working environment, hard labor, poor safety and low efficiency. In the paper, the current status of the automated pipe handling system is firstly introduced, and the advantages and disadvantages of these automated pipe handling systems are expounded. Then the comparative analysis of applicability, complexity and the retrofitting cost of the automated pipe picked-up and laid-down drilling floor device, pipe handling device on racking board and the offline stand building device in both domestic and foreign are made. Finally, the suitable types of automated pipe handling system can be used to retrofit servicing rigs in China are pointed out. Cameron's automatic up-and-down rig device, Weatherford's racking board automatic pipe handling system and National Drilling Company's offline stand building system are most suitable for the automation retrofitting of servicing rigs. The results show that, these automated pipe handling systems can not only reduce the labor of field operators, improve pipe handling efficiency, reduce the retrofitting workload of servicing rig, but also save retrofitting costs. The retrofitted servicing drilling rigs will be with new vitality and play a greater role in the development of ultra-deep wells and unconventional oil and gas in China.
\end{abstract}

Keywords: Automated Pipe Handling, Retrofit Servicing Rigs, Pipe Picked-Up and Laid-Down Device, Robot Derrickman, Offline Stand Building System

\section{Introduction}

Automation technology has been developing vigorously in many industries such as aerospace and automobile. However, the development of automation in oil and gas exploration and development industry is lagging behind. Under the current low oil price cycle, there are many challenges such as increasingly stringent requirements for safety and environmental protection, rising costs, increasing difficulties in oil well development and shortage of trained personnel. Solving these problems is the primary problem facing petroleum researchers [1]. The application of automatic drilling equipment started late in China's petroleum industry equipment industry, most of which are semi-mechanized and semi-automated. Although it has played a good role in reducing labor intensity and improving safety and security, there is still a considerable gap compared with foreign advanced automated drilling equipment.

\section{Discussion}

There is no best technology, but only the most appropriate technology. At present, some research has been done on rig retrofitting in China. With regard to the retrofitting of mechanical drilling rigs into electric drilling rigs, $\mathrm{Wu}$ 
Weizhou (2018) analyzed the current main models of old drilling rigs, and put forward feasible remanufacturing plans for the retrofitting of power grid system, energy conservation and emission reduction of drilling rigs [2], so as to carry out technical innovation on the old drilling rigs in a targeted manner. The whole machine can meet the economic and applicable requirements under the current environmental protection and the requirements of moderate humanization and automation after retrofitting. Ma Weidong (2018) provided high-voltage mobile substation for the drilling rig, and carried out technical retrofitting for some drilling rigs, and better economic and social benefits are achieved [3]. Zhang Huijie (2019) retrofitted the old rig with an automatic drilling system [4].

There are few domestic and foreign literatures on the rig automation retrofitting. Sun Changzheng (2019) added power catwalk, floor manipulator, iron roughneck, power rat hole, power slip, and automatic elevator on the servicing drilling rig based on domestic technology, which was difficult, long-term and expensive [5].

\section{Automatic Pipe Picked-up and Laid-down Drilling Floor Device}

Automatic Pipe handling system mainly includes two parts, one is picking up the pipe from the ground to the drilling floor or laying down from the drilling floor to the ground, and the other is the pipe handling on the drilling floor. At present, there are fixed power catwalk, lifting power catwalk, parallel connecting rod power catwalk and overturning manipulator (Figure 1 to Figure 5) [6 10], which can transfer drilling string (drill pipe, collar and casing, etc.) from the ground to the certain position on drilling floor or from drilling floor to the ground pipe rack. Only a small number of personnel or no manual assistance is required. Some of these automatic picked-up and laid-down drilling floor devices have been used on fully automated rigs, and most of them can only be used on semi-mechanized and semi-automated rigs, or for the retrofitting of servicing rigs. These devices can also measure, record and calculate the length of drill string automatically by infrared ray at the same time. They can be operated by remote control or by manual touch screen in driller's control room. The labor intensity of field workers can be greatly reduced, the safety and efficiency of pipe handling can be improved, and the drill pipe joint thread is also protected.

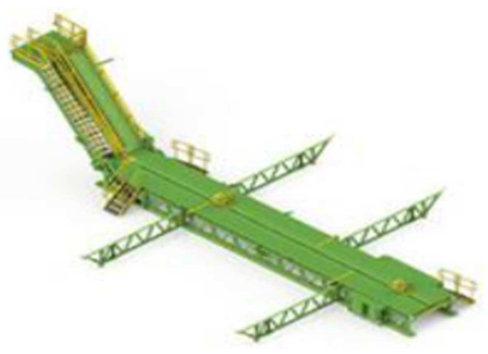

Figure 1. Fixed automatic catwalk.

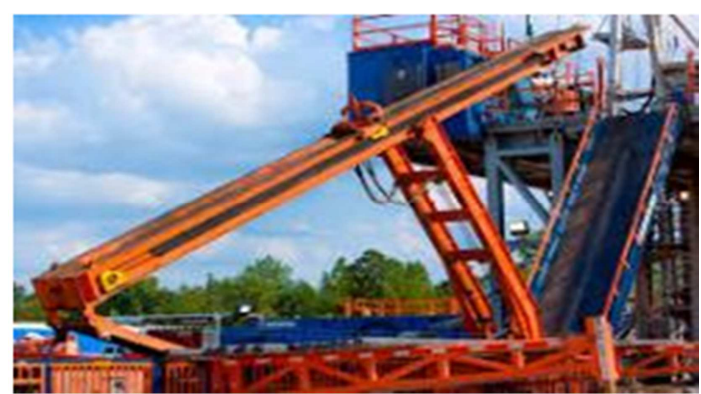

Figure 2. Lift automatic catwalk.

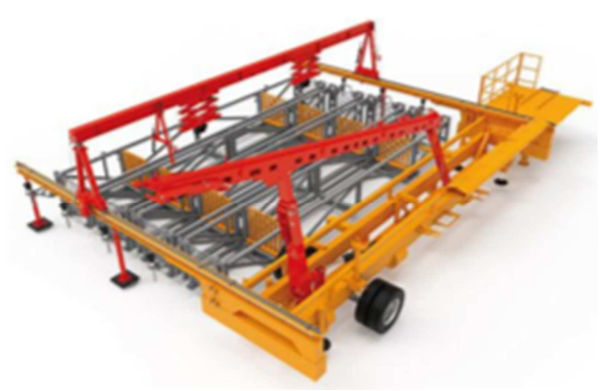

Figure 3. Parallel connecting rod power catwalk.

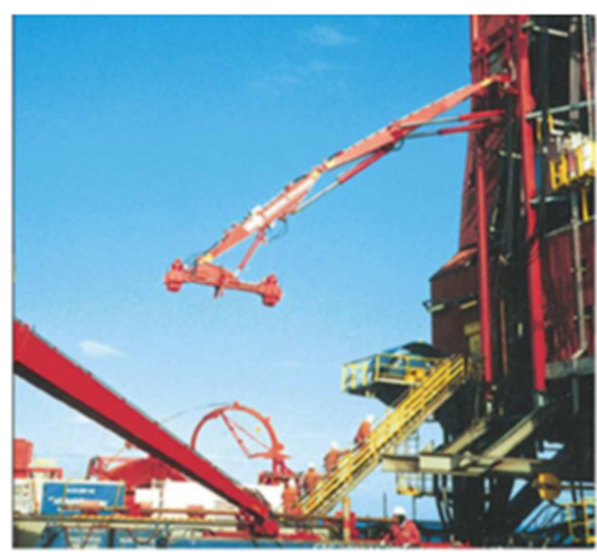

Figure 4. Eagle horizontal to vertical Device.

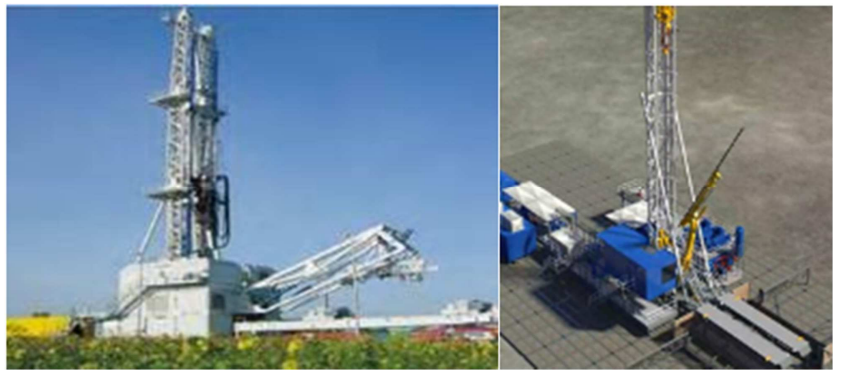

Figure 5. Turn-over automatic pipe picked-up and laid-down drilling floor device.

These automatic picked-up and laid-down devices have their own characteristics, which can improve the safety performance of field operation, reduce the time of pipe pick-up and laid-down drilling floor, and improve production efficiency. But a common disadvantage in these automatic pick-up and laid-down drilling floor is only suitable for a certain type of rig or a certain height of rig. For different drilling floor layout, height and wellhead center distance, a 
specification of automatic picked-up and laid-down device is difficult to adapt. A large number of retrofitting must be made on the drilling floor or the picked-up and laid-down devices before they can be used.

In the land drilling market, there are many kinds of automatic picked-up and laid-down devices including some serialized ones, but the multi-functional automatic devices are rare. For different types of drilling rigs and various heights of drilling floor, the existing automatic picked-up and laid-down devices lack flexibility. Cameron International recently introduced a new type of automatic picked-up and laid-down device (Figure 6) for various types of rigs and drilling floor heights (Table 1) [11]. The unique design of the automatic picked-up and laid-down device optimizes the angle of the pipe entering the drilling floor. It can not only transfer drill pipe, collar and casing between the ground and the drilling floor, but also can safely and effectively transfer various drilling floors and downhole tools, such as casing pliers, stabilizers short joints and bits by using the integrated telescopic manipulator.

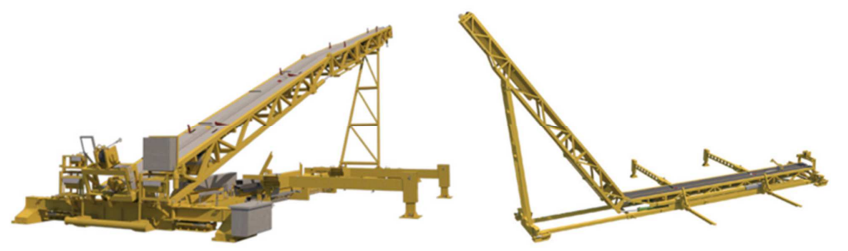

Figure 6. Multifunctional automatic pipe picked-up and laid-down drilling floor device.

Table 1. Types of drilling rigs suitable for multi-function automatic catwalk.

\begin{tabular}{|c|c|c|c|c|c|}
\hline Rig Type & ZJ40 & ZJ 50 & ZJ 70 & ZJ 80 & ZJ 90 \\
\hline Substructure Height (m) & 6 or 7.5 & 7.5 or 9 & $7.5,9$ or 10.5 & 10.5 & 12 \\
\hline Maximum Hook load (kN) & 2250 & 3150 & 4500 & 5850 & 6750 \\
\hline
\end{tabular}

The multi-functional automatic device has many unique advantages and functions. There are two integrated cylinders with lifting hinges between the catwalk and the ramp. The angle of pipe entering the drilling floor can be adjusted arbitrarily by the cylinder. There is no connection between ramp and drilling floor. The thrust unit of the automatic catwalk is used to adjust the position of the pipe in the ramp, and the thread cleaning device, greasing device and thread protection device are designed. When the drill tool is on the drilling floor, the pipe is fed into the catwalk from the ground pipe rack. Driven by the driving device located at the end of the catwalk, the pipe moves toward the ramp. At the same time, the lifting cylinder on the base lifts the catwalk, and the driving cylinder between the catwalk and the ramp extends to adjust the position of the ramp. According to the height of drilling floor, the angle between catwalk and ramp can be adjusted to transport and receive single drill pipe, collar and casing. The drill pipe conveying system is installed on the opposite side of the driller, which can push a single rod onto the ramp. The casing conveying system is located at the driller's side, and the front end of the string is pushed forward by a pusher, which is connected by a top drive sling or a drilling rig pipe handling system. The process of laying down the drilling tool is contrary. Its main technical parameters are as follows.

Table 2. Technical parameters of automatic pipe picked-up and laid-down drilling floor device.

\begin{tabular}{lll}
\hline NO. & Name & Parameters \\
\hline 1 & Power & $230 \mathrm{VAC}$, \\
2 & Hydraulic consumption & $350 \mathrm{~L} / \mathrm{min}$ \\
3 & temperature range & -20 to $55^{\circ} \mathrm{C}$ \\
& & $31 / 2 \sim 13 \% / 8$ in $(89 \sim$ \\
5 & Diameter range & $346 \mathrm{~mm}])$ \\
5 & Maximum length of string transportation & $14 \mathrm{~m}$ \\
6 & Maximum transfer speed & $1.5 \mathrm{~m} / \mathrm{s}$ \\
7 & Maximum travel of telescopic manipulator & $3.80 \mathrm{~m}$ \\
\hline
\end{tabular}

In addition, the automatic picked-up and laid-down drilling rig is equipped with angle sensor and length laser in the cylinder. The control system also integrates the database of the pipe, and all kinds of data about the string (length, type, running hours, etc.) can be stored, and the position of each string in the vertical box or wellhead center can be tracked. This system can exactly show the number and total length of drill pipe and whether there are non-shearing parts in BOP. Drill pipe tracking record list does not need to be kept by drillers.

The automatic picked-up and laid-down device is also equipped with an integrated walking system, which can move in both vertical and horizontal directions. The integrated lifting device ensures that the ramp structure can be safely and effectively deployed. The telescopic arm is installed on the ramp near the end of the drilling floor and can be used as a mechanical arm. The device has the following advantages and characteristics:

(1) A ramp with a driving device is used to transfer pipes between the ground and the drilling floor adopts. The casing and drill pipe conveying devices on both sides of the driller are used for the transmission of the string without manual operation.

(2) The integrated mechanical arm replaces the base lifting equipment by which the casing tongs, stabilizers, joints and other tools can be moved between the ground and the rig floor.

(3) The walking device is equipped to adjust the best working position of the equipment.

(4) The anti-collision system is equipped.

(5) The wireless portable control box is convenient and flexible, which can be operated remotely or in the driller's room with a higher automation control.

(6) The priority based security alarm system is designed.

(7) The firm structure can deal with the bad environment and the drill floor with various heights.

In summary, this kind of automatic picked-up and laid-down device has wide applicability, simple retrofitting, 
complete functions, high degree of automation and low cost, which is most suitable for the automatic retrofitting of servicing drilling rigs in China.

\section{Pipe Handling Device on Racking Board}

The pneumatic (or spring) fingerboard, racking board manipulator, automatic elevator and drill floor manipulator are used to replace the derrickman and the floorman to move the upper and lower ends of the stand to the fingerboard and the drill floor setback box respectively, or the robot derrick man is used to put the string directly into the fingerboard and the setback box, so that unmanned operation of racking board and drilling floor can be realized. At present, the commonly used pipe handling devices at home and abroad are push-type, suspension type, snatch type and other structural forms [12 16] (Figure 7 to Figure 11). After cooperate with power catwalk and iron roughneck, the risk of field personnel exposed to dangerous places is reduced, the labor intensity of the second floor platform, drilling platform and ground operation personnel is greatly reduced, and the unmanned operation of the second floor platform can be realized.

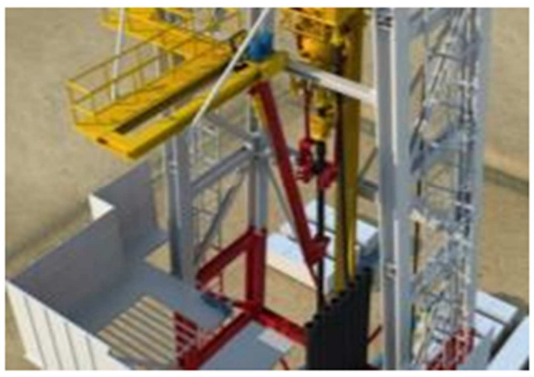

Figure 7. Push-type pipe handling device on racking board.

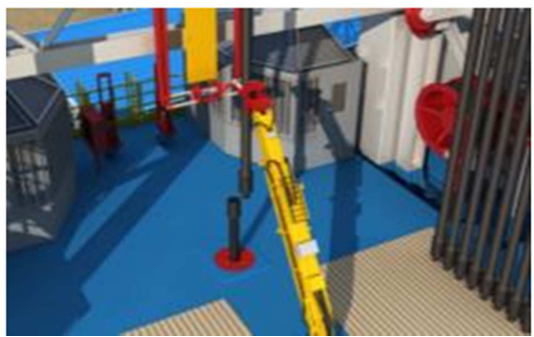

Figure 8. Manipulator on drilling floor.

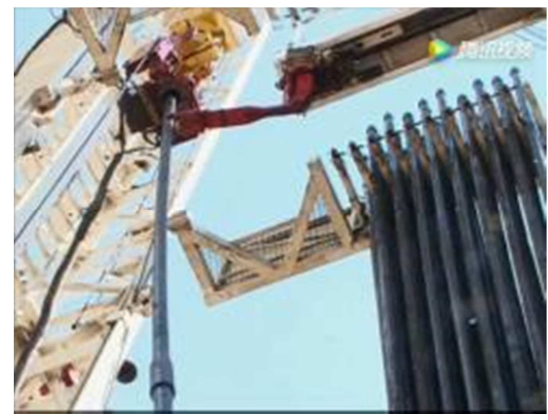

Figure 9. Push-type pipe handling system on racking board for workover rig

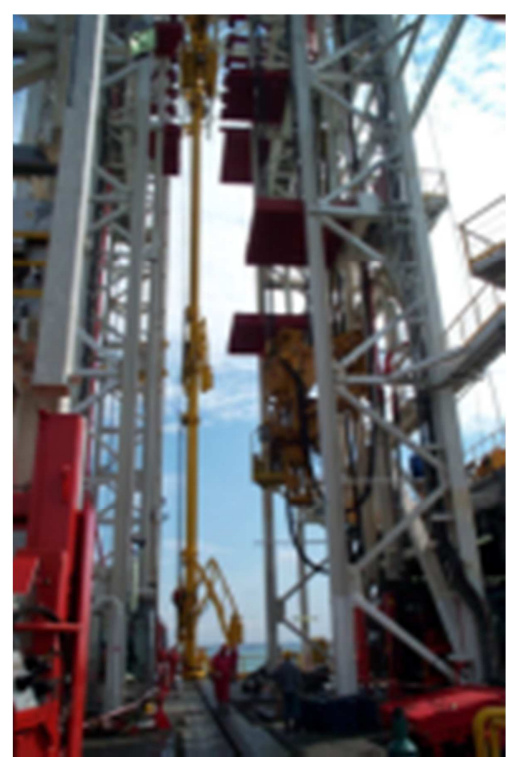

Figure 10. Grab-type pipe handling device.

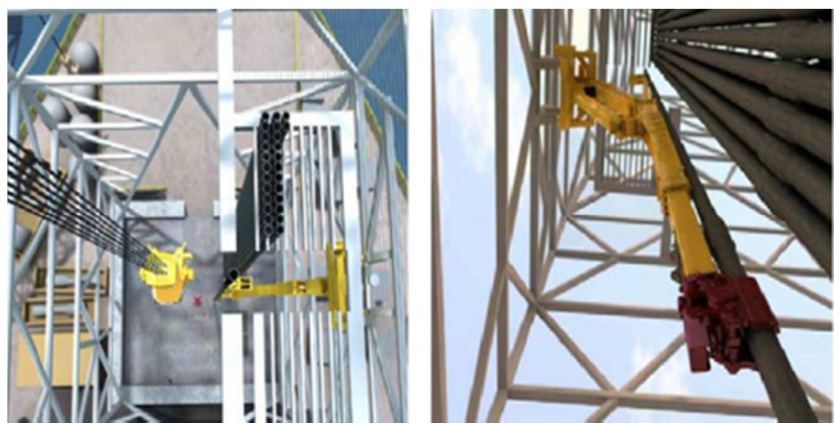

Figure 11. Suspension-type pipe handling device.

These automatic pipe handling devices all have good effects when they are used in new drilling rigs, but the high cost, the heavy workload of the retrofitting and poor safety and reliability are shown when it is used for the retrofitting of servicing drilling rigs.

In recent years, a new type of racking board pipe handling device [17] (Robot Derrickman) has been introduced abroad. The device (Figure 12) makes use of industrial robot technology, and the automatic derrickman can be installed on double or triple rigs with only a slight change to the racking board. It is suitable for land rigs and smaller offshore drilling with handling all kinds of stands from 2-7 / 8 "to 8-1 / 4" and the maximum weight of $6800 \mathrm{~kg}$.
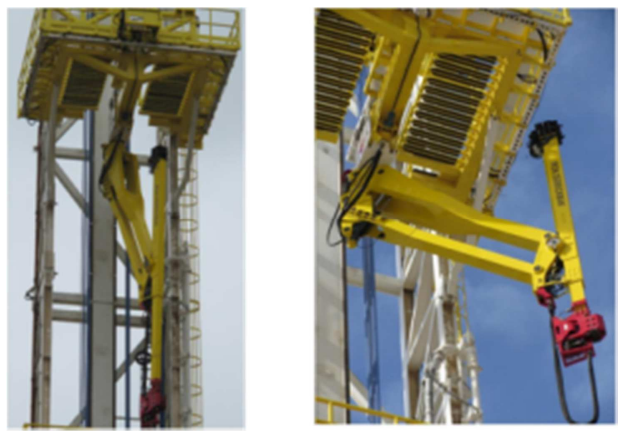

Figure 12. Automatic pipe handling system on racking board. 
After retrofitting, the automatic pipe handling device is installed under the racking board of the existing conventional drilling rig, which can bear its own weight and the weight of the pipe. During operation, through the electrical controller installed in the driller's room or external wireless remote control, the following procedures can be followed to discharge the drill pipe stub, thickened drill pipe or drill collar into the designated finger beam. Firstly, it receives the pipe from the hydraulic elevator, retracts and vertically lifts it, and then moves in three axial directions at the same time to control the pipe moving to the target position in the fingerboard of the racking board. The automation pipe handling on the racking board without a derrick man can be realized. When it is used with iron roughneck, fully unmanned pipe handling on drilling floor and racking board can be realized. Because the operating system is programmed by PLC, it can also be integrated into existing or new integrated control management system. If the system fails or the manual operation is required, the derrickman can operate from the traditional position without removing it.

The operation in North America for nearly 5 years at $-46^{\circ} \mathrm{C}$ shows that the tripping speed of this racking board automatic pipe handling system is close to that of the most experienced derrickman and better than that of the inexperienced ones. Compared with manual operation, the system can run 40 to 45 stands per hour continuously, and its safety and long-term stability are much higher than manual operation. It is easier to complete the operator training due to the simplicity of operation, which marks a significant progress in the unmanned handling of pipe on conventional rigs. The low cost also makes this kind of racking board automatic pipe handling system very suitable for the automation retrofitting of servicing drilling rigs in China.

\section{Offline Stand Building Device}

There are two purposes for the automation of pipe handling. One is to ensure the safety of the operators of the drilling floor and the racking board, and the other is to improve the efficiency of operation. If the pipe automatic picked-up and laid-down device and the racking board pipe handling device mentioned above cooperate with the iron roughneck, the derrickman and floorman can be basically replaced and the safety and stability of the operation have also been greatly improved. However, the operation efficiency can be further improved, because the drilling process requires a long time to connect single. If triple are connected at the wellhead each time instead of a single, the stand is established offline, so two-thirds of the connection time can be saved.

At present, the offline stand building method of conventional drilling rigs in China is carried out through the cooperation of pneumatic winch and derrickman. This method has large swing of drill pipe, sometimes there are risks such as interference of wire rope and falling objects in high altitude. Moreover, the auxiliary operation of derrickman is needed on the racking board. The two air winches on the rig floor need to be operated, and the operators are completely exposed to the high risk area of operation, which brings great safety hazards [18 20].

Recently, the National Drilling Company adopted an automatic pipe handling system and an offline stand building device for drilling operations on an artificial island (there are nine rigs). The offline stand building device (Figure 13) is a simple and applicable crane. By installing an elevated gantry over the racking board, the stands can be built and supported simultaneously without interrupting the wellhead drilling operation. The crane composed of three parts (bridge, pulley and beam) is composed of two special main beams, which provide support and slide rails to cross the bridge horizontally above monkey board. The pulley crosses the bridge horizontally and lifts the stands with hydraulic winches. The combined movement of crane and bridge moves the stands to the storage position of the setback box or finger beam. The offline stand building device also includes two revolving rat holes, a base type of iron roughneck and a power catwalk.

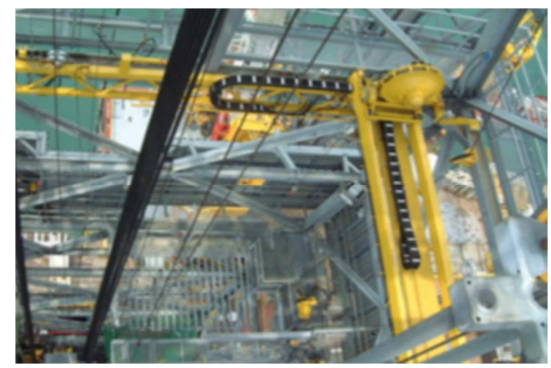

Figure 13. Offline stands building device of the National Drilling Company.

The process of offline stand building is as follows:

(1) Single elevator is used, and the pulley assembly can pick up a single, build stand from the power catwalk and place it in rotary rathole 1 .

(2) The second canal column was lifted and placed in rotary rathole 2 .

(3) The third pipe is then lifted and aligned with the drill pipe located in rotary rathole 1 .

(4) Two joints are connected by rotating by using the rotation characteristics of rotary rathole 1 .

(5) Tighten the joint to the required make-up torque by the iron roughneck.

(6) Two new singles are put into rotary rathole 2.

(7) Connecting with an iron driller.

(8) Then the stands are placed in the finger beam or setback box by the lifting device.

According to this order of offline stand building, every stands is put into the finger beam or setback box, and all the stands are built and discharged into the finger beam at the same time of drilling operation. After drilling one stand, one triple stand can be taken directly from the racking board and connected to the wellhead drill string by an iron roughneck, instead of only one single at a time. In this way, each triple stand can be connected with two less joints, and a lot of time is saved to connect stands. By cooperating with automated catwalk and iron roughneck, the device can build stand 
offline without any interference to drilling operation. Statistics on two of these rigs show that the offline stand building system saves a total of 748,000 US dollars in six months. In addition, the low cost also makes this type of offline stand building system very suitable for the automation retrofitting of active drilling rigs in China.

\section{Conclusion}

(1) With the continuous development of automatic pipe handling equipment, various new automatic drilling rigs continue to bring forth new ideas, and the unmanned operation of the racking board and drilling floor have been fully realized. This is the development trend of future drilling rigs, and also the goal of future research and development of drilling equipment in China. But for the servicing land rigs, most of the rigs in our country are still semi-mechanized, and quite a number of rigs are still fully manual operation. Applying the new and low-cost technology of the automatic drilling equipment to the servicing drilling rig can not only reduce the labor and risk of field workers, but also improve the safety and drilling efficiency.

(2) The automation retrofitting of servicing rigs is to get the maximum benefit with the minimum cost. By comparison, Cameron's automatic up-and-down rig device, Weatherford's racking board automatic pipe handling system and National Drilling Company's offline stand building system are most suitable for the current automation retrofitting of servicing rigs in China.

(3) To adapt to the industrial drilling operation, the drilling rig must be able to move rapidly between adjacent wells in the same well pad, and it is necessary to equip with a rig walking system.

(4) With the development of economy and technology, there will be other pipe handling equipment more suitable for China's rig retrofitting in the future, which needs to be studied in time.

(5) With the retrofitting of oil and gas development to deep, low permeability and unconventional resources, the automation retrofitting of China's servicing drilling rigs is a huge market. International drilling equipment companies should take the chance to achieve win-win results with China's drilling contractors.

\section{Acknowledgements}

The authors would like to thank the China National Science and Technology Major Project "Automated Drilling Technology and Equipment for Deep and Ultra-deep Wells" (2016ZX05020-001) and the CNPC Scientific Research and Technological Development Project "Key Technical Equipment for Continuous Tripping Drilling" (2016B-4001) for the grant in writing the paper.

\section{References}

[1] Wang Haige, Wang Lingbi, Ji Guodong, etc. Advances in well drilling and completion technologies for domestic and overseas [J]. Oil Drilling \& Production Technology. 2013, 35 (05): 1-12.

[2] Wu Weizhou, Liu Zhilin, Liu Yuanbo, etc. Feasibility Analysis of Old Rig Remanufacturing Technology [J]. Mechanical Engineer. 2018, 46 (05): 79-83.

[3] Ma Weidong. Analysis of the Technology and Economic Benefit of "Electricity Replacing Oil" for Drilling Rig [J]. Plant Maintenance Engineering. 2018, 19 (16): 8-10.

[4] Zhang Huijie, Liang Weigang, Yuan Jian. Retrofit Plan for Automatic Drilling System of Oil Drilling Rig [J]. Plant Maintenance Engineering. 2019, 20 (16): 103-105.

[5] Sun Changzheng, Li Jinfu, Li Haiying. Technology and Practice of Automatic Pipe Handling Upgrading of Drilling Rig in Service [J]. West-China Exploration Engineering. 2019, 31 (02): 48-52.

[6] Chang Yulian, Jiang Kaixun, Fanyansong, etc. Technological Development of Pipe handling System in Drilling and Workover Operation [J]. Petroleum Machinery. 2012, 40 (01): 87-90.

[7] Liu Chunbao, Wang Dingya, Wang Yaohua, et al. Design and Test of DM3/3.3-J Hydraulic Cylinder Lifting Power Catwalk [J]. Petroleum Machinery. 2016, 44 (09): 41-46.

[8] Li Yanjiao, Yu Ping, Gao Jianqiang, et al. Dynamic Analysis Of Hoisting System of the New Automatic Catwalk [J]. Oil Field Equipment. 2015, 44 (05): 1-5.

[9] Wang Jie, Qian Liqin, Chen Xinlong, et al. Dynamic Model and Analysis of The Lifting System of Automatic Catwalk [J]. Chinese Journal of Engineering Design. 2016, 23 (05): 437-443.

[10] Lu Junkang, Tanjian, Li Yahui, et al. Design and Application of Wheeled Moving Raised Catwalk [J]. Petroleum Machinery. 2018, 46 (01): 21-26.

[11] Trond Loeyning. Automated Catwalk Machine for Land Rigs [C]. SPE 188752.2017.

[12] Wang Dingya, Wang Yaohua, Yu Xingjun. Research and Development Trend of Domestic Automated Drilling Rig [J]. Petroleum machinery. 2017, 45 (05): 23-27.

[13] Wang Dingya, Zhang Zengnian, Wang Ruhua, et al. Research and Development Suggestion for Automatic Push-support Pipe Handling System [J]. Petroleum Machinery. 2018, 46 (09): 1-6.

[14] Zhu Haidong, Zhu Keqiang, Tan Haibo. Virtual Prototype Design of Pipe-handling Robot on Racking Platform [J]. Oil Field Equipment. 2016, 45 (6): 51-53.

[15] Herrenknecht VerticaL GMBH, Pipe Handling Modernization Package, available: https://www.herrenknecht-vertical.com/.

[16] Jim Vogt. Automated Racking Board Pipe Handling System for Drilling Rigs Ensures Connection Integrity While Providing Safer Working Conditions and Consistent Tripping Speeds With Minimal Rig Modifications [C]. SPE 176336.2015 
[17] Weatherford International Ltd., Iron Derrickman ${ }^{\circledR} \mathrm{S} 3$ Pipe-Handling System, available: https://www.weatherford.com/.

[18] Chaima Belbaraka, Osama Abd Elnaby. Safer, Faster and Efficient Operations through Operation Offline Stand Building: A Case Study [C]. SPE 188645.2017.
[19] Ugasciny, A., Chang, B. T, Hampson, A.. Cost Reduction on Onshore Rig Operation with Offline Stand Building System [C]. SPE 181292, 2016.

[20] Guo Xiaoyan, Huang Lijing, Du Yongjun, et al. The Application of the Double-mouse Hole Stand Building Offline System on Land Rig [J]. Petroleum Machinery. 2017, 45 (10): 32-37. 